\title{
Impact of The Distal Resection Margin On Local Recurrence After Neoadjuvant Chemoradiation and Rectal Excision For Locally Advanced Rectal Cancer
}

\section{Seung Ho Song}

Colorectal Cancer Center, Kyungpook National University Chilgok Hospital, School of Medicine, Kyungpook National University, Daegu

\section{Jun Seok Park ( $\sim$ parkjs0802@knu.ac.kr)}

Colorectal Cancer Center, Kyungpook National University Chilgok Hospital, School of Medicine, Kyungpook National University, Daegu

\section{Gyu-Seog Choi}

Colorectal Cancer Center, Kyungpook National University Chilgok Hospital, School of Medicine, Kyungpook National University, Daegu

\section{An Na Seo}

Department of Pathology, Kyungpook National University Chilgok Hospital, School of Medicine, Kyungpook National University, Daegu

\section{Soo Yeun Park}

Colorectal Cancer Center, Kyungpook National University Chilgok Hospital, School of Medicine, Kyungpook National University, Daegu

Hye Jin Kim

Colorectal Cancer Center, Kyungpook National University Chilgok Hospital, School of Medicine, Kyungpook National University, Daegu

\section{Sung-Min Lee}

Colorectal Cancer Center, Kyungpook National University Chilgok Hospital, School of Medicine, Kyungpook National University, Daegu

\section{Ghilsuk Yoon}

Department of Pathology, Kyungpook National University Chilgok Hospital, School of Medicine, Kyungpook National University, Daegu

\section{Research Article}

Keywords: Rectal cancer, Chemoradiotherapy, Distal resection margin, Local recurrence

Posted Date: May 13th, 2021

DOI: https://doi.org/10.21203/rs.3.rs-478899/v1 
License: (c) (i) This work is licensed under a Creative Commons Attribution 4.0 International License. Read Full License

Version of Record: A version of this preprint was published at Scientific Reports on November 25th, 2021. See the published version at https://doi.org/10.1038/s41598-021-02438-1. 


\section{Abstract}

We aimed to evaluate whether a short distal resection margin $(<1 \mathrm{~cm})$ was associated with local recurrence in patients with locally advanced rectal cancer who underwent preoperative chemoradiotherapy. Patients with rectal cancer who underwent preoperative chemoradiotherapy followed by curative surgery were divided into two groups based on the distal resection margin ( $\geq 1 \mathrm{~cm}$ and $<1$ $\mathrm{cm})$. In total, 507 patients were analyzed. The median follow-up duration was 48.9 months. The 3-year local recurrence rates were $2 \%$ and $8 \%$ in the $\geq 1 \mathrm{~cm}$ and $<1 \mathrm{~cm}$ groups, respectively $(p<0.001)$. Multivariable analysis revealed that a distal resection margin of $<1 \mathrm{~cm}$ was a significant risk factor for local recurrence $(p=0.008)$. Subgroup analysis revealed that a distal resection margin of $<1 \mathrm{~cm}$ was not an independent risk factor for local recurrence in the ypT0-1 group. However, among patients with tumor stages ypT2-4, the cumulative 3-year incidences of local recurrence were $2.3 \%$ and $9.8 \%$ in the $\geq 1 \mathrm{~cm}$ and $<1 \mathrm{~cm}$ groups, respectively $(p=0.001)$. A distal resection margin of $<1 \mathrm{~cm}$ might influence local recurrence rates in patients with locally advanced rectal cancer undergoing preoperative chemoradiotherapy, especially in patients with tumor stages ypT2-4.

\section{Introduction}

Ensuring an adequate distal resection margin (DRM) is necessary to save the sphincter in patients with locally advanced rectal cancer (LARC) [1, 2]. The National Comprehensive Cancer Network guidelines state that a negative DRM of 1-2 cm might be acceptable [1], and current Japanese guidelines recommend a DRM of $\geq 2 \mathrm{~cm}$ in patients with lower rectal cancers at stages 0-III [2]. However, in routine clinical practice, it is sometimes technically difficult to follow these guidelines for such cases. Occasionally, margins that are thought to be sufficient during the initial surgery have been reported to be shorter than that anticipated. Even among patients receiving preoperative chemoradiotherapy (CRT), unpredictable tumor shrinkage and residual tumor patterns make it difficult to decide on an acceptable DRM after surgery $[3,4]$.

Various studies have investigated the optimal DRM needed to achieve acceptable oncologic outcomes after sphincter-saving surgery for LARC [5-8]. Although a DRM of $<1 \mathrm{~cm}$ might not be associated with specific oncologic outcomes, according to a systematic review [9], the authors emphasized that the specific rules for patients and tumor selection need to be evaluated. To our knowledge, few studies have evaluated the impact of DRM on local recurrence after preoperative CRT and according to the ypT tumor stage. Herein, we aimed to evaluate whether a short DRM $(<1 \mathrm{~cm})$ was associated with local recurrence in patients with LARC who underwent preoperative CRT. We compared oncologic outcomes according to the DRM and performed subgroup analysis according to the ypT stage.

\section{Results}

\section{Clinical Characteristics}


Overall, 507 patients with LARC underwent preoperative CRT and rectal excision (Fig. 1). Patient characteristics are summarized in Table 1. For the DRM dimensions, there were 418 patients in the $\geq 1$ $\mathrm{cm}$ group and 89 in the $<1 \mathrm{~cm}$ group. Tumor height (from the anal verge) was significantly greater in the $\geq 1 \mathrm{~cm}$ group than in the $<1 \mathrm{~cm}$ group $(6.0 \mathrm{~cm}$ vs. $2.5 \mathrm{~cm} ; p<0.001)$. Significantly more patients with advanced clinical T stage tumors were included in the $\geq 1 \mathrm{~cm}$ group than in the $<1 \mathrm{~cm}$ group (clinical stages T3-4, $99.3 \%$ vs. $94 \%, p<0.001)$.

Table 1

Patient characteristics. DRM, distal resection margin. ASA, American Society of Anesthesiologists

\begin{tabular}{|llll|}
\hline & $\begin{array}{l}\text { DRM } \geq 1 \mathrm{~cm} \\
(\mathbf{n = 4 1 8})\end{array}$ & $\begin{array}{l}\text { DRM }<1 \mathrm{~cm} \\
(\mathbf{n = 8 9})\end{array}$ & $\boldsymbol{p}$ \\
\hline Age, years & $62.0(55.0-71.0)$ & $60.0(53.0-69.0)$ & 0.16 \\
\hline Sex & & & 0.21 \\
\hline Male & $254(60.8 \%)$ & $61(68.5 \%)$ & \\
\hline Female & $164(39.2 \%)$ & $28(31.5 \%)$ & \\
\hline ASA classification & & & \\
\hline 1 & $233(55.7 \%)$ & $53(59.6 \%)$ & \\
\hline 2 & $181(43.3 \%)$ & $36(40.4 \%)$ & $<0.001$ \\
\hline 3 & $4(1.0 \%)$ & - & $<0.001$ \\
\hline Tumor height, cm & $6.0(4.0-8.0)$ & $2.5(2.0-4.2)$ & \\
\hline Clinical T stage & & & 0.22 \\
\hline T2 & $3(0.7 \%)$ & $5(5.6 \%)$ & \\
\hline T3 & $339(81.1 \%)$ & $79(88.8 \%)$ & \\
\hline T4 & $76(18.2 \%)$ & $5(5.6 \%)$ & \\
\hline Clinical N stage & & $66(74.2 \%)$ & \\
\hline N0 & $81(19.4 \%)$ & & \\
\hline N+ & $337(80.6 \%)$ & & \\
\hline
\end{tabular}

\section{Operative and Pathologic Outcomes}

Operative and pathologic findings are summarized in Table 2. The most common type of operation was intersphincteric resection in the $<1 \mathrm{~cm}$ group (61\%). Pathologic tumor depth differed significantly between the groups: $70.6 \%$ of patients in the $\geq 1 \mathrm{~cm}$ group had ypT3-4 disease, while $47 \%$ of patients in the $<1 \mathrm{~cm}$ group had yрT3 disease. No patients in the $<1 \mathrm{~cm}$ group had ypT4 grade tumors. The rate of 
pathologic nodal positivity was significantly higher in the $\geq 1 \mathrm{~cm}$ group than in the $<1 \mathrm{~cm}$ group (39.7\% vs. $16 \% ; p<0.001)$. Circumferential resection margin (CRM) positivity rates were similar between the two groups $(9.6 \%$ vs. $9 \% ; p=1.00)$. The pathological complete response rate differed significantly between the $\geq 1 \mathrm{~cm}$ and $<1 \mathrm{~cm}$ groups ( $12.7 \%$ vs. $24 \% ; p=0.01$ ). In addition, good tumor response rates (tumor regression grade [TRG] 3 and 4 ) differed between the $\geq 1 \mathrm{~cm}$ and $<1 \mathrm{~cm}$ groups $(49.8 \%$ vs. $71 \% ; p<$ $0.001)$.

Table 2

Operative and pathologic findings. DRM, distal resection margin. LAR, low anterior resection. ISR, intersphincteric resection. APR, abdominoperineal resection. CRM = circumferential resection margin.

\begin{tabular}{|c|c|c|c|}
\hline & $\begin{array}{l}\text { DRM } \geq 1 \mathrm{~cm} \\
(n=418)\end{array}$ & $\begin{array}{l}\mathrm{DRM}<1 \mathrm{~cm} \\
(\mathrm{n}=89)\end{array}$ & $p$ \\
\hline Type of operation & & & $<0.001$ \\
\hline LAR & $286(68.4 \%)$ & $35(39.3 \%)$ & \\
\hline ISR & $105(25.1 \%)$ & $54(60.7 \%)$ & \\
\hline APR & $27(6.5 \%)$ & - & \\
\hline Tumor size, $\mathrm{cm}$ & $3.2(2.0-4.5)$ & $2.5(1.8-3.3)$ & $<0.001$ \\
\hline Lymphovascular invasion & $32(7.7 \%)$ & $3(3.4 \%)$ & 0.22 \\
\hline Venous invasion & $32(7.7 \%)$ & $4(4.5 \%)$ & 0.41 \\
\hline Pathologic stage & & & $<0.001$ \\
\hline ypTONO & $45(10.8 \%)$ & $21(23.6 \%)$ & \\
\hline ypTON+ & $6(1.4 \%)$ & - & \\
\hline I & $60(14.4 \%)$ & $24(27.0 \%)$ & \\
\hline II & $147(35.2 \%)$ & $30(33.7 \%)$ & \\
\hline III & $160(38.3 \%)$ & $14(15.7 \%)$ & \\
\hline CRM, positive $(\leq 1 \mathrm{~mm})$ & $40(9.6 \%)$ & $8(9.0 \%)$ & 1.00 \\
\hline Tumor regression grade & & & 0.002 \\
\hline 0 (no regression) & $6(1.5 \%)$ & $2(2.3 \%)$ & \\
\hline 1 (minor regression) & $52(12.9 \%)$ & $8(9.2 \%)$ & \\
\hline 2 (moderate regression) & $144(35.8 \%)$ & $15(17.2 \%)$ & \\
\hline 3 (good regression) & $149(37.1 \%)$ & $41(47.1 \%)$ & \\
\hline 4 (total regression) & $51(12.7 \%)$ & $21(24.1 \%)$ & \\
\hline
\end{tabular}




\section{Survival Outcomes}

The median follow-up period was 48.9 months ( 46.9 months in the $\geq 1 \mathrm{~cm}$ group versus 54.8 months in the $<1 \mathrm{~cm}$ group). Cumulative incidences of local recurrences at 3 years were $2 \%$ (95\% confidence interval $(\mathrm{Cl}), 0.6-3.3 \%)$ for the $\geq 1 \mathrm{~cm}$ group and $8 \%(95 \% \mathrm{Cl}, 2.2-14 \%)$ for the $<1 \mathrm{~cm}$ group $(p<0.001$; Fig. 2A), indicating a significant difference. Cumulative incidences of distant metastasis at 3 years were $22.8 \%(95 \% \mathrm{Cl}, 18.6-26.8 \%)$ for the $\geq 1 \mathrm{~cm}$ group and $23 \%(95 \% \mathrm{Cl}, 13.8-31.8 \%)$ for the $<1 \mathrm{~cm}$ group ( $p$ $=0.80)$. The 5-year disease-free survival (DFS) rates were similar between the two groups $(74.4 \%$ vs. $70 \%$; $p=0.71$; Fig. 2B). Local recurrences were seen in the central region in six patients and in the pelvic sidewall in two patients in the $<1 \mathrm{~cm}$ group; three and five patients showed local recurrence in the central region and pelvic sidewall, respectively, in the $\geq 1 \mathrm{~cm}$ group.

In the subgroup analysis, in the ypT0-1 group, cumulative incidences of local recurrences at 3 years were $0 \%$ for the $\geq 1 \mathrm{~cm}$ group and $4 \%(95 \% \mathrm{Cl}, 0-12.3 \%)$ for the $<1 \mathrm{~cm}$ group ( $p=0.12 ; \mathrm{Fig}$. 3A); in the ypT2-4 group, the incidences were $2.3 \%(95 \% \mathrm{Cl}, 0.7-3.9 \%)$ for the $\geq 1 \mathrm{~cm}$ group and $9.8 \%(95 \% \mathrm{Cl}, 2.0-20.7 \%)$ for the $<1 \mathrm{~cm}$ group $(p=0.001$; Fig. 3B).

The results of univariate and multivariable analyses of risk factors for local recurrence are listed in Table 3. Local recurrence was significantly associated with the DRM dimension (odds ratio $[O R]=4.57$, $95 \% \mathrm{Cl} 1.48-14.5)$ and $\mathrm{CRM}$ status $(\mathrm{OR}=4.77,95 \% \mathrm{Cl} 1.35-15.3)$. In patients with ypT2-4, a short DRM $(<1 \mathrm{~cm})$ was an independent risk factor for local recurrence $(\mathrm{OR}=4.33,95 \% \mathrm{Cl} 1.34-14.0$, Supplemental Table S1). We could not find any significant risk factor associated with local recurrence in patients with ypT0-1 grade tumors. The results of risk factor analysis for local recurrence among patients with a negative CRM $(>1 \mathrm{~mm})$ showed that a short DRM $(<1 \mathrm{~cm})$ was significant risk factors for local recurrence $(\mathrm{OR}=5.15,95 \% \mathrm{Cl} 1.38-20.4$, Supplemental Table S2). 
Table 3

Univariate and multivariable analysis of risk factors for local recurrence in patients with locally advanced rectal cancer who underwent preoperative chemoradiotherapy followed by rectal excision. CRM, circumferential resection margin. DRM, distal resection margin.

\begin{tabular}{|c|c|c|c|c|c|c|}
\hline \multirow[t]{2}{*}{ Characteristic } & \multicolumn{3}{|c|}{ Univariate } & \multicolumn{3}{|c|}{ Multivariable } \\
\hline & OR & $95 \% \mathrm{Cl}$ & $\mathbf{p}$ & OR & $95 \% \mathrm{Cl}$ & p \\
\hline Sex (male) & 1.35 & $\begin{array}{l}0.48 \\
4.35\end{array}$ & 0.60 & & & \\
\hline Age (> 60 years) & 0.67 & $\begin{array}{l}0.24 \\
1.82\end{array}$ & 0.40 & & & \\
\hline Tumor height $(<5 \mathrm{~cm})$ & 2.94 & $\begin{array}{l}1.05 \\
9.46\end{array}$ & 0.048 & 1.84 & $\begin{array}{l}0.56 \\
6.61\end{array}$ & 0.31 \\
\hline Clinical stage, T4 & 0.75 & $\begin{array}{l}0.12 \\
2.74\end{array}$ & 0.71 & & & \\
\hline Clinical stage, $\mathrm{N}+$ & 3.98 & $\begin{array}{l}0.79 \\
72.4\end{array}$ & 0.21 & 4.75 & $\begin{array}{l}0.90 \\
87.7\end{array}$ & 0.14 \\
\hline урт3,4 * & 1.10 & $\begin{array}{l}0.39 \\
3.55\end{array}$ & 0.93 & & & \\
\hline $\mathrm{ypN}+*$ & 1.09 & $\begin{array}{l}0.37 \\
2.99\end{array}$ & 0.94 & & & \\
\hline $\begin{array}{l}\text { Histologic type (mucinous or } \\
\text { signet-ring cell) }\end{array}$ & 6.48 & $\begin{array}{l}0.33 \\
43.6\end{array}$ & 0.10 & 10.4 & $\begin{array}{l}0.49 \\
85.1\end{array}$ & 0.05 \\
\hline Positive CRM ( $\leq 1 \mathrm{~mm})$ & 4.74 & $\begin{array}{l}1.44 \\
13.7\end{array}$ & 0.006 & 4.77 & $\begin{array}{l}1.35 \\
15.3\end{array}$ & 0.01 \\
\hline $\operatorname{DRM}(<1 \mathrm{~cm})$ & 5.06 & $\begin{array}{l}1.81 \\
14.1\end{array}$ & 0.002 & 4.57 & $\begin{array}{l}1.48 \\
14.5\end{array}$ & 0.008 \\
\hline Lymphovascular invasion & 0.90 & $\begin{array}{l}0.05 \\
4.63\end{array}$ & $>0.9$ & & & \\
\hline Venous invasion & 1.92 & $\begin{array}{l}0.29 \\
7.25\end{array}$ & 0.41 & & & \\
\hline
\end{tabular}

\section{Discussion}

Although international guidelines recommend that a 1-2-cm DRM might be acceptable in patients with LARC [1, 2], it is difficult to obtain a sufficient DRM for sphincter-saving surgery in patients with mid/low rectal cancer receiving preoperative CRT. In a systematic review that analyzed 5,574 patients with rectal cancer from 17 studies, a short DRM $(<1 \mathrm{~cm})$ was observed in $948(17.0 \%)$ patients [9]. In the Lyon R9001 trial, $36.1 \%(43 / 119)$ of patients had a DRM of $<1.5 \mathrm{~cm}$ [10]. Among the patients with a suspected margin of $<1 \mathrm{~cm}$ after specimen extraction, we were unable to predict which of them had a risk of an adverse oncologic outcome. Even when the intraoperatively suspected DRM is not sufficient, it is 
technically challenging to perform additional rectal resection after a distal one. There are few published data on the impact of a short DRM on local recurrence in patients with LARC who underwent preoperative $\mathrm{CRT}$, and the results are conflicting. Furthermore, very few investigators have directly evaluated the association between a short DRM and local recurrence, according to the ypT stage. We found that a short DRM $(<1 \mathrm{~cm})$ was associated with local failure in patients with LARC receiving preoperative CRT; this was distinctly observed in patients with ypT2-4 tumors.

In the short DRM group $(<1 \mathrm{~cm})$, over half of those who developed local recurrence had a relapse in the central region, such as the presacral region, or at the anastomosis. The reasons for this are uncertain; however, some researchers have reported that residual cancer cells might be associated with local recurrence in the central pelvis, such as in the presacral region, or at the anastomosis within the radiation field [11-14]. These studies suggested that it might be related to the resection margin or tears at the tumor site. Upon microscopic analysis, tumor cells were noted to be scattered in nonuniform and unpredictable patterns after preoperative CRT [3]. Furthermore, tumor cells were present under normalappearing mucosa in approximately $36-71 \%$ of cases, and the distance varied by up to $3-4 \mathrm{~cm}[3,4]$. They raised concerns that the distal margin could be invisible after preoperative CRT. Taken together, these findings indicate that a short DRM might be associated with local recurrence in the central region.

It is noteworthy that the impact of a short DRM $(<1 \mathrm{~cm})$ on local recurrence was observed in patients with yрT2-4 stages disease. In contrast, such a short DRM was not a significant risk factor for local recurrence in patients with ypT0-1 stage tumors. We believe this difference arose from the various effects of CRT and different distal mural spreading patterns according to tumor stage. Some investigators have reported increased distal spread with increasing tumor stage $[4,15]$. Shimada et al. reported that the maximum distances of distal spread were 4, 16, and $20 \mathrm{~mm}$ in tumor stages I, II, and III, respectively [15]. Smith et al. analyzed patients with LARC who underwent preoperative CRT and reported that the median and maximum microscopic tumor spread for ypT1 grade tumors were 0 and $4 \mathrm{~mm}$, those for ypT2 were 2.5 and $9 \mathrm{~mm}$, and those for ypT3 were 4 and $9 \mathrm{~mm}$, respectively [4]. These results and those of our study reinforce the importance of achieving a sufficient DRM in patients suspected of having advanced ypT stage tumors.

To our knowledge, there are no guidelines on the indications for adjuvant treatment and treatment strategies for patients with close or positive DRM after preoperative CRT and sphincter-preserving surgery. Recent guidelines have suggested that intraoperative radiation therapy might be considered for very close or positive margins after resection, as an additional boost $[1,16]$. Kusters et al. reported the effectiveness of intraoperative radiotherapy for local control in patients with LARC [14]. Some investigators recommend adjuvant chemoradiation or salvage APR for patients with a pathologically invaded resection margin [17]. In cases of ypT2-4 stage tumors with a short DRM, more intensified combined treatment modalities, such as booster radiation, oxaliplatin-based chemotherapy, and closer follow-up, should be considered after multidisciplinary team meetings. 
Pathologic CRM involvement is a well-known predictive factor for local recurrence, which could have influenced our results $[18,19]$. Therefore, we analyzed independent risk factors for local recurrence with and without the CRM as a variable. Regardless of the pathologic CRM status, a short DRM $(<1 \mathrm{~cm})$ was demonstrated to be a significant risk factor for local recurrence. This was also observed in the subgroup analysis of patients with ypT2-4 stage tumors.

\section{Limitations}

This study had some limitations; it was retrospective, and bias was possible in terms of case selection. Despite this, our results were contrary to what was expected in terms of the characteristics of both groups. In detail, the local recurrence rate was higher in the short DRM $(<1 \mathrm{~cm})$ group, which represents a favorable stage than the long DRM ( $\geq 1 \mathrm{~cm}$ ) group. We did not analyze the results based on both intramural and mesorectal distal spread. Previous studies on DRM have described different methodologies to measure the resection margin status [9], and some have focused on whole-mount histopathology analyses to evaluate the DRM [15, 20,21]. However, our routine histopathology examinations were performed according to the international standard reporting form. Therefore, our results might reflect real clinical practices. To the best of our knowledge, this study includes the largest reported number of patients (over 500) with LARC who underwent preoperative CRT. Moreover, we adopted strict criteria for neoadjuvant treatments and analyzed the results based on ypT staging.

In conclusion, a DRM of $<1 \mathrm{~cm}$ might lead to local treatment failure in patients with LARC who underwent preoperative CRT. This was clearly observed in patients with ypT2-4 tumors. Adjuvant treatment agreed upon through multidisciplinary team conferences should be considered in patients with ypT2-4 grade tumors and a short DRM.

\section{Methods}

\section{Patients}

The study was approved by our institutional review board (KNUCH 2020-04-034). In accordance with the institution's guidelines and regulations for retrospective study, the institutional review board waived the requirement for informed consent (institutional review board of Kyungpook National University Chilgok Hospital). We performed this study according to the Declaration of Helsinki.

We analyzed data from our hospital's prospectively collected colorectal cancer registry for patients treated between January 2011 and March 2017. We reviewed patients with rectal cancers located within $12 \mathrm{~cm}$ from the anal verge during initial imaging and who underwent neoadjuvant CRT. Patients with stage IV tumors were excluded. Tumor location was assessed using digital examination, rigid sigmoidoscopy, or pelvic magnetic resonance imaging (MRI). All patients underwent physical examinations and chest, abdominal, and pelvic computed tomography (CT) and pelvic MRI. After 
neoadjuvant CRT, restaging was performed 6-7 weeks later via pelvic MRI and chest, abdominal, and pelvic CT.

\section{Neoadjuvant Treatments}

Neoadjuvant CRT was recommended for patients with cT tumors of any N1-2 stage or CT3-4N0 disease. Patients underwent concurrent CRT, comprising a total irradiation dose of 45-50.4 Gy, delivered at 2 Gy per day, 5 days per week for 5 weeks, and concurrent chemotherapy included a continuous infusion of 5-fluorouracil (5-FU)/leucovorin or oral capecitabine. During the study period, the most common chemotherapeutic regimens consisted of $5-\mathrm{FU} 425 \mathrm{mg} / \mathrm{m}^{2}$ intravenous bolus plus leucovorin $20 \mathrm{mg} / \mathrm{m}^{2}$ intravenous bolus for 4 days, during weeks 1 and 5 of radiation, or oral capecitabine $825 \mathrm{mg} / \mathrm{m}^{2}$ twice daily, 5 days per week for 5 weeks. Surgery was scheduled 7-9 weeks after the completion of radiation.

\section{Surgical Procedures}

Patients underwent mechanical bowel preparation before surgery. A standard total mesorectal excision was performed as described previously [22,23]. We performed a high ligation of the inferior mesenteric artery, medial-to-lateral mobilization of the left colon, complete mobilization of the splenic flexure, and sharp dissection of the pelvis with a nerve-sparing technique. Selective lateral pelvic lymph node dissection was performed in patients with suspected lateral pelvic node metastases identified using initial imaging [24]. Sphincter-saving was performed in all patients, except when the levator ani muscle had been invaded by the tumor. Our policy was a DRM is $>2 \mathrm{~cm}$ for upper and mid rectal cancers. For low rectal cancers, we attempted to achieve a distal clearance margin of ${ }^{3} 0.5 \mathrm{~cm}$ for sphincter preservation. Anastomosis was performed using either double-stapled, end-to-end, or hand-sewn techniques, except for abdominoperineal resections (APRs). All procedures were performed by four experienced surgeons (G.S.C., J.S.P., S.Y.P., and H.J.K.) who have each performed over 100 colorectal cancer surgeries per year.

\section{Histopathology}

The surgical specimens were first inspected externally to locate the tumor, and the presence of any obvious perforation was recorded intraoperatively [25]. The specimens were then transferred to the pathology department and examined by two specialist pathologists (G.S.Y. and A.N.S.) with $>10$ years of experience in colorectal cancer pathology. The non-peritonealized surface of the specimen was marked with green ink to enable subsequent identification of the CRM. After this, the specimen was opened along the anterior aspect and fixed in a large volume of $10 \%$ neutral-buffered formalin overnight. Subsequently, the tumor size and distance of the tumor from the proximal and distal resection margins were measured. The DRM was defined as the distance between the lower edge of the primary rectal cancer to the resection margin of the specimen. In the case of stapled anastomoses, donut rings were not included in the measurement but were examined microscopically to determine the involvement of any viable tumor cells. If proximal or distal resection margins of $£ 1.5 \mathrm{~cm}$ were detected visually, appropriate blocks were selected to cover the closest approximation to those margins and then evaluated microscopically. The 
CRM was defined as the closest distance from the outermost part of the viable tumor cells to the inked resected specimen. The CRM was measured using a microscope graticule or ruler, and CRM negativity was defined as a distance of $>1 \mathrm{~mm}$ [26]. The pathologic stage of each tumor was assigned following the guidelines from the $7^{\text {th }}$ edition of the American Joint Committee on Cancer staging manual for colorectal cancers [27]. Regression of the primary tumor in response to neoadjuvant CRT was assessed based on the TRG, as described by Rodel et al. [28].

\section{Adjuvant Chemotherapy}

The most common adjuvant chemotherapeutic regimens were four more cycles of fluorouracil and leucovorin (fluorouracil $400-425 \mathrm{mg} / \mathrm{m}^{2}$ per day plus leucovorin $20 \mathrm{mg} / \mathrm{m}^{2}$ per day on days $1-5$, every 4 weeks) or eight more cycles of modified FOLFOX 6 (oxaliplatin $85 \mathrm{mg} / \mathrm{m}^{2}$ on day 1 , leucovorin $400 \mathrm{mg}$ total dose over $2 \mathrm{~h}$ on day 1 , fluorouracil $400 \mathrm{mg} / \mathrm{m}^{2}$ bolus on day 1 , followed by $2,400 \mathrm{mg} / \mathrm{m}^{2}$ over $46 \mathrm{~h}$, every 2 weeks).

\section{Follow-up}

Patients were followed up via clinical examination; blood assays for carcinoembryonic antigen; and chest, abdominal, and pelvic CT every 3 months within the first 2 years and every 6 months thereafter. Patients routinely underwent colonoscopy in the first and fourth years after surgery. Local recurrence was defined as recurrent disease within the true pelvis with or without distant metastases and classified into central (anastomotic, anterior, presacral, and perineal) and lateral (pelvic sidewall) recurrence [11,12]. Distant recurrence was defined as recurrence beyond the locoregional area.

\section{Statistical Analysis}

Continuous variables were first tested for normality (Shapiro-Wilk Normality test). The two groups based on DRM ( $\geq 1 \mathrm{~cm}$ and $<1 \mathrm{~cm}$ ) were compared using two-sample Student's $t$ tests or Kruskal-Wallis Rank Sum tests. Categorical variables were assessed using the chi-square test or Fisher's exact test. Logistic regression was applied to multivariable analysis to identify independent risk factors for local recurrence. Variables with a $p$-value of $<0.2$ in the univariate analysis were selected for the multivariable analysis. DFS was defined as the period from the date of initial surgery to the date of disease recurrence or death. Time to local recurrence was calculated from the date of initial surgery until local recurrence was noted; patients with no recurrence were censored at the date of the last follow-up, or at death. Patient survival was estimated using the Kaplan-Meier method, and survival curves were compared using a log-rank test. All analyses were conducted using the R project for Statistical Computing, Version 4.0.1 (R Development Core Team, Vienna, Austria; https://www.r-project.org), and $p$ values $<0.05$ were considered statistically significant.

\section{Declarations}

\section{ACKNOWLEDGEMENTS}




\section{AUTHOR CONTRIBUTIONS}

SHS was responsible for analysis of data and writing of the manuscript; JSP and G-SC carried out correspondence and initiated the study proposal; and ANS, SYP, HJK, SML, and GSY were responsible for patient enrollment, data collection, and study proposal.

\section{ADDITIONAL INFORMATION}

Funding statement. This work was supported by the National Research Foundation of Korea (NRF) grant funded by the Korean government (MSIP) (No. 2020R1A2C1010750).

Competing interests. The authors declare no competing interests.

Ethics approval statement. This study was approved by the institutional review board (KNUCH 2020-04034).

\section{Data availability}

The datasets used and analysed during the current study are available from the corresponding author on reasonable request.

\section{References}

1. National Comprehensive Cancer Network: NCCN Clinical Practice Guidelines in Oncology: Rectal cancer (version 2.2020). Available at http://www.nccn.org/professionals/physician_gls/recently_updated.aspx. Accessed November 20, 2020.

2. Hashiguchi, Y. et al. Japanese Society for Cancer of the Colon and Rectum (JSCCR) guidelines 2019 for the treatment of colorectal cancer. Int J Clin Oncol. 25, 1-42 (2020).

3. Hayden, D. M. et al. Tumor scatter after neoadjuvant therapy for rectal cancer. Dis Colon Rectum. 55, 1206-1212 (2010).

4. Smith, F. M., Wiland, H., Mace, A., Pai, R. K. \& Kalady, M. F. Depth and lateral spread of microscopic residual rectal cancer after neoadjuvant chemoradiation: implications for treatment decisions. Colorectal Dis. 16, 610-615 (2014).

5. Kuvshinoff, B. et al. Distal margin requirements after preoperative chemoradiotherapy for distal rectal carcinomas: are $\leq 1 \mathrm{~cm}$ distal margins sufficient? Ann Surg Oncol. 8, 163-169 (2001).

6. Rutkowski, A. et al. Distal bowel surgical margin shorter than $1 \mathrm{~cm}$ after preoperative radiation for rectal cancer: is it safe? Ann Surg Oncol. 15, 3124-3131 (2008).

7. Pricolo, V. E., Abodeely, A. \& Resnick, M. Distal margins in radical resections for rectal cancer after chemoradiation therapy: how short is long enough. Dig Surg. 27, 185-189 (2010). 
8. Kim, Y. W. et al. Factors associated with anastomotic recurrence after total mesorectal excision in rectal cancer patients. J Surg Oncol. 99, 58-64 (2009).

9. Bujko, K. et al. Is the 1-cm rule of distal bowel resection margin in rectal cancer based on clinical evidence? A systematic review. Ann Surg Oncol. 19, 801-808 (2012).

10. Francois, Y. et al. Influence of the interval between preoperative radiation therapy and surgery on downstaging and on the rate of sphincter-sparing surgery for rectal cancer: the Lyon R90-01 randomized trial. J Clin Oncol. 17, 2396 (1999).

11. Kusters, M. et al. Patterns of local recurrence in rectal cancer; a study of the Dutch TME trial. Eur J Surg Oncol. 36, 470-476 (2010).

12. Enríquez-Navascués, J. M. et al. Patterns of local recurrence in rectal cancer after a multidisciplinary approach. World J Gastroenterol. 17, 1674-1684 (2011).

13. Kusters, M. et al. A comparison between the treatment of low rectal cancer in Japan and the Netherlands, focusing on the patterns of local recurrence. Ann Surg. 249, 229-235 (2009).

14. Kusters, M. et al. Patterns of local recurrence in locally advanced rectal cancer after intra-operative radiotherapy containing multimodality treatment. Radiother Oncol. 92, 221-225 (2009).

15. Shimada, Y., Takii, Y., Maruyama, S. \& Ohta, T. Intramural and mesorectal distal spread detected by whole-mount sections in the determination of optimal distal resection margin in patients undergoing surgery for rectosigmoid or rectal cancer without preoperative therapy. Dis Colon Rectum. 54, 15101520 (2011).

16. You, Y. N. et al. The American Society of Colon and Rectal Surgeons Clinical practice guidelines for the management of rectal cancer. Dis Colon Rectum. 63, 1191-1222 (2020).

17. Tilly, C. et al. R1 rectal resection: look up and don't look down. Ann Surg. 260, 794-800 (2014).

18. Quirke, P., Durdey, P., Dixon, M. F. \& Williams, N. S. Local recurrence of rectal adenocarcinoma due to inadequate surgical resection. Lancet. 2, 996-999 (1986).

19. Baik, S. H. et al. Prognostic significance of circumferential resection margin following total mesorectal excision and adjuvant chemoradiotherapy in patients with rectal cancer. Ann Surg Oncol. 14, 462-469 (2007).

20. Nakagoe, T. et al. Distal intramural spread is an independent prognostic factor for distant metastasis and poor outcome in patients with rectal cancer: a multivariate analysis. Ann Surg Oncol. 10, 163170 (2003).

21. Mezhir, J. J. et al. Whole-mount pathologic analysis of rectal cancer following neoadjuvant therapy. Ann Surg. 256, 274-279 (2012).

22. Park, J. S., Choi, G. S., Jun, S. H., Hasegawa, S. \& Sakai, Y. Laparoscopic versus open intersphincteric resection and coloanal anastomosis for low rectal cancer. Ann Surg. 254, 941-946 (2011).

23. Park, J. S., Choi, G. S., Lim, K. H., Jang, Y. S. \& Jun, S. H. S052: A comparison of robot-assisted, laparoscopic, and open surgery in the treatment of rectal cancer. Surg Endoscopy. 25, 240-248 (2011). 
24. Kim, H. J. et al. Optimal treatment strategies for clinically suspicious lateral pelvic lymph node metastasis in rectal cancer. Oncotarget. 8, 100724-100733 (2017).

25. The Royal College of Pathologists: Standards and datasets for reporting cancers Dataset for histopathological reporting of colorectal cancer September 2018. Available at https://www.rcpath.org/uploads/assets/c8b61ba0-ae3f-43f1-85ffd3ab9f17cfe6/G049-Dataset-forhistopathological-reporting-of-colorectal-cancer.pdf. Accessed November 20, 2020.

26. Hwang, M. R. et al. Prognostic impact of circumferential resection margin in rectal cancer treated with preoperative chemoradiotherapy. Ann Surg Oncol. 21, 1345-1351 (2014).

27. Edge, S. B. \& Compton, C. C. The American Joint Committee on Cancer: the 7th edition of the AJCC cancer staging manual and the future of TNM. Ann Surg Oncol. 17, 1471-1474 (2010).

28. Rödel, C. et al. Prognostic significance of tumor regression after preoperative chemoradiotherapy for rectal cancer. J Clin Oncol. 23, 8688-8696 (2005).

\section{Figures}

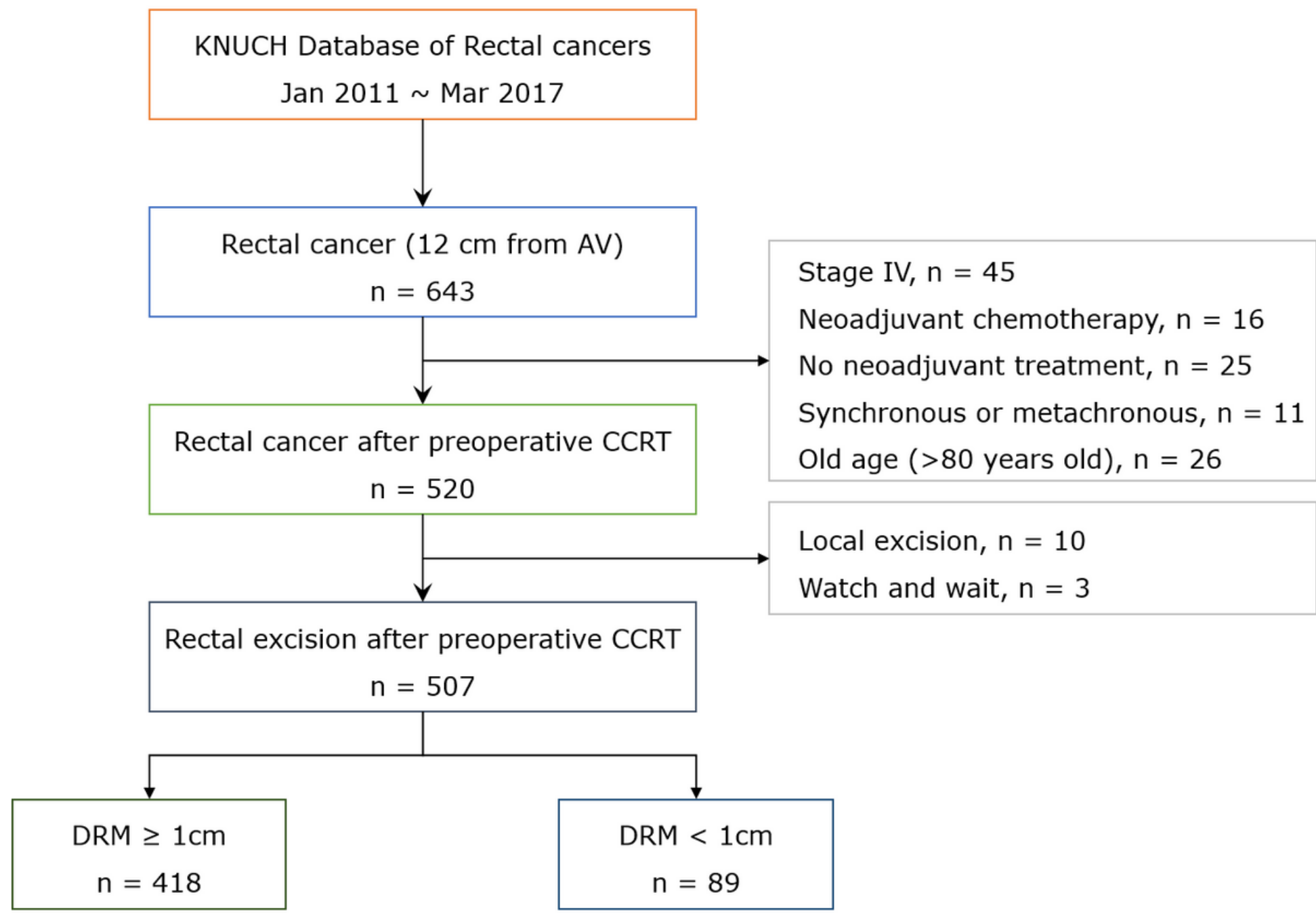

Figure 1 
Study flow diagram

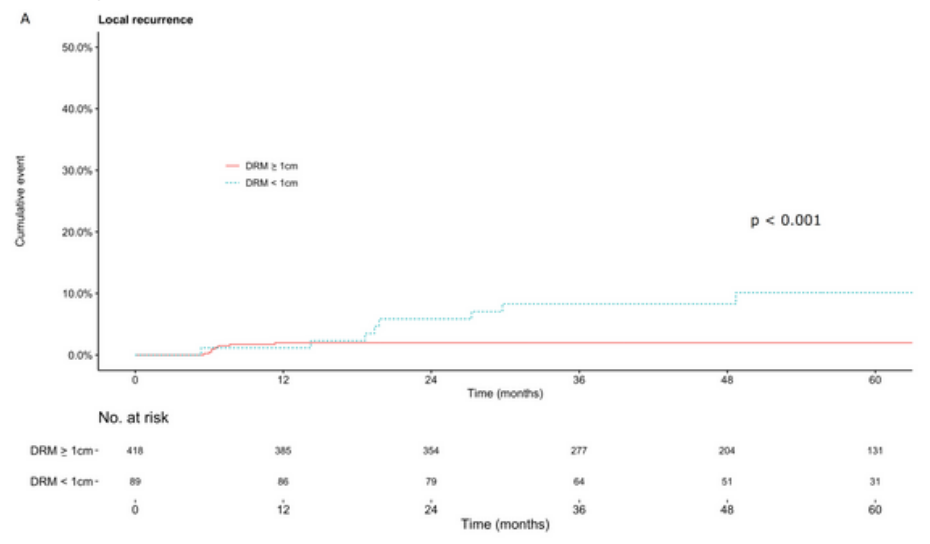

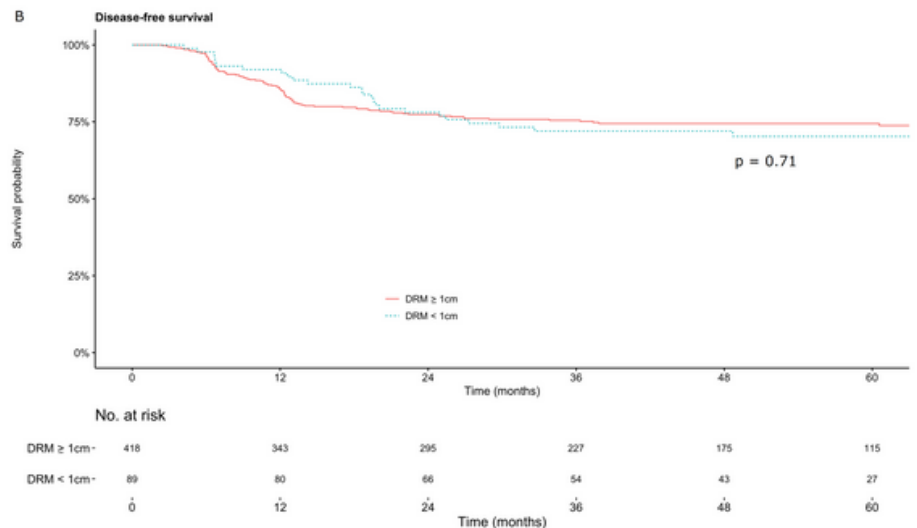

\section{Figure 2}

Cumulative incidence of local recurrence (a) and disease-free survival (b) in patients with locally advanced rectal cancer who underwent preoperative chemoradiotherapy followed by rectal excision
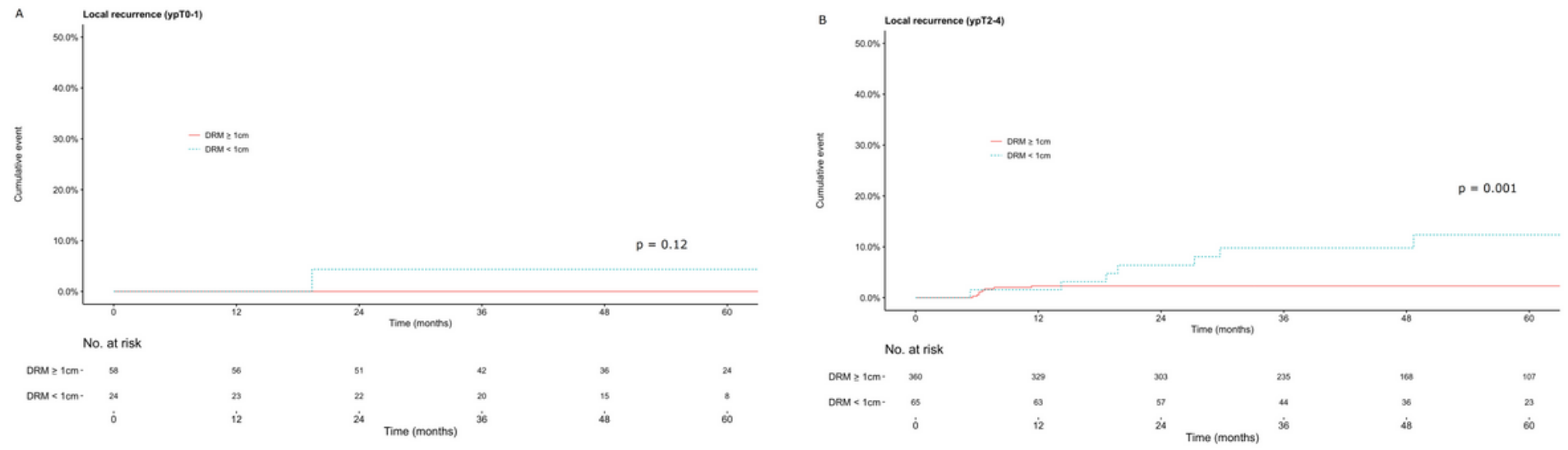

\section{Figure 3}

Cumulative incidence of local recurrence in patients with rectal cancer ypT0-1 (a) and ypT2-4 (b)

\section{Supplementary Files}

This is a list of supplementary files associated with this preprint. Click to download.

- DRM2supplement210511.pdf 